\title{
Novel Bioceramic Scaffolds for Regenerative Medicine
}

\section{Hannickel A and Prado da Silva $\mathbf{M H}^{*}$}

Military Institute of Engineering-IME, Brazil

\begin{abstract}
Calcium phosphate ceramics have been used as synthetic grafts for bone repair. This family of alloplastic grafts is an alternative to allografts (from other individuals from the same specie), autografts (from the same individual) or xenografts (from individuals from other species). Sintered bovine bone is basically composed mainly by hydroxyapatite $(\mathrm{HA}), \mathrm{Ca}_{10}\left(\mathrm{PO}_{4}\right)_{6}(\mathrm{OH})_{2}$ but chemical analyses indicate the presence of $\mathrm{Mg}$. Chemical and heat treatments are generally required to eliminate biological hazard. However, the more crystalline hydroxyapatite, the less resorbable the product is. An approach to have a highly crystalline and still resorbable material is to use additions of alpha or beta tricalcium phosphate, $\mathrm{Ca}_{3}\left(\mathrm{PO}_{4}\right)_{2}$, (TCP). The addition of fractions of some bioactive glasses to hydroxyapatite has shown to be effective in promoting its decomposition to tricalcium phosphate. In addition, glass reinforced hydroxyapatite composite are materials with higher compressive strength due to liquid phase sintering. In this study, novel scaffolds based on hydroxyapatite and tricalcium phosphate are presented.
\end{abstract}

\section{Keywords: Scaffold; Bone; Hydroxyapatite}

\section{Introduction}

Bone is a dynamic tissue, which undergoes healing after severe injuries, since favourable conditions are present. Large bone defects require grafts that can guide bone to grow though their structure and also interact with cells and tissues inducing osteogenesis [1]. Bone grafts can be autogenous, allogenous, xenogenous or alloplastic [2]. Autografts come from the same individual, whereas allografts are bone from other individuals from the same specie. Xenografts are derived from individuals from other species. Synthetic or alloplastic grafts were first designed to be osteoconductive, i.e. e., able to conduct growth of the newly formed bone tissue throughout the pores of the structure [3-6]. Porous bioceramics, bioactive glasses and glass-ceramics are examples of biomaterials used for bone reconstruction. Hydroxyapatite ( $\mathrm{HA},\left(\mathrm{Ca}_{10}\left(\mathrm{PO}_{4}\right)_{6}(\mathrm{OH})_{2}\right)$, is the most well characterised bioceramic. There are several studies on HA bioactivity, i.e. e., the ability to chemically bonding to living bone. However, medical applications of HA are restricted to sites of low-to-medium load-bearing applications. Glass-reinforced hydroxyapatite, GR-HA, is still bioactive and can have higher fracture toughness than pure HA. GR-HA can be produced by mixing $\mathrm{HA}$ and bioactive glasses. When a $\mathrm{CaO}-\mathrm{P}_{2} \mathrm{O}_{5}$ based glass is added to hydroxyapatite (HA) and sintered, the glassy phase reacts with HA. The present phases will depend on the sintering temperature and the glass composition. It is particularly beneficial to have bioresorbable phases like beta tricalcium phosphate $(\beta$-TCP) and alpha tricalcium phosphate $(\alpha-\mathrm{TCP})$, as these phases are known to be more soluble than HA [7].

Bioactive glass and ceramics can be used as granules or porous scaffolds in applications where bone ingrowth is needed or as scaffolds for tissue engineering [8]. Porous biomaterials based on ceramics and glass ceramics have been produced by several techniques such as the use of impregnated polymeric sponges, foaming processes and techniques using organic additives $[9,10]$. The main morphological requisites for allowing bone ingrowth are the existence of open and interconnected pores, with pore diameters larger than $100 \mu \mathrm{m}$ for proper vascularisation and fluid circulation. The interconnectivity of the pores can be achieved by controlling both moulding and sintering processes. However, there is a compromise between interconnectivity and mechanical strength [11].

In this study, two patented scaffolds are presented: polyurethane sponge coated with hydroxyapatite and bovine bone reinforced with bioactive glass $[12,13]$. In both cases, there are hydroxyapatite and tricalcium phosphate after sintering. Alpha and beta TCP are more resorbable phases when compared to pure hydroxyapatite. The presence of a biphasic or triphasic structure enhances bio-resorption and is a tool to design scaffolds with resorption rates close to that of new bone formation.

The aim of this study was to design porous scaffolds with potential to be used as bone fillers and as supports for tissue engineering. Both morphological and micro structural properties were carefully designed to meet the requirements of pore size and distribution, interconnectivity, bioactivity and resorption rate. Ongoing studies are assessing the osteoinductive potential of these materials.

\section{Methodology}

The scaffolds derived from polyurethane sponges are obtained by a coating process, which consists of the deposition of monetite, $\mathrm{CaHPO}_{4}$, on porous blocks (scaffolds) with variable dimensions. The scaffolds were hydrothermally coated with monetite and further converted to hydroxyapatite by an alkali treatment with $\mathrm{NaOH}$. The starting solution has the following composition: $0.3 \mathrm{M} \mathrm{H}_{3} \mathrm{PO}_{4}, 0.5 \mathrm{M} \mathrm{Ca}(\mathrm{OH})_{2}$, $1 \mathrm{M} \mathrm{C}_{3} \mathrm{H}_{6} \mathrm{O}_{3}$ (lactic acid). The monetite coating was produced by the immersion of the specimens in the solution at $80^{\circ} \mathrm{C}$ during 1 hour. The sponges were then removed, washed in ultra-pure water and dried in an oven at $60^{\circ} \mathrm{C}$. The coatings were then converted to hydroxyapatite by immersion in a solution of $0.1 \mathrm{M} \mathrm{NaOH}$ during 24 hours at $60^{\circ} \mathrm{C}$. Specimens were then removed from the alkali solution, washed in ultra-pure water and dried in an oven at $100^{\circ} \mathrm{C}$. After drying, the blocks were sintered at $1300^{\circ} \mathrm{C}$. The heating rates were $0.5^{\circ} \mathrm{C} / \mathrm{min}$ up to $550^{\circ} \mathrm{C}$ and $5^{\circ} \mathrm{C} / \mathrm{min}$ up to the sintering temperature.

*Corresponding author: Prado da Silva MH, Military Institute of Engineering-IME Brazil, E-mail: marceloprado@ime.eb.br

Received November 26, 2014; Accepted January 07, 2015; Published January 25,2015

Citation: Hannickel A, Prado da Silva MH (2015) Novel Bioceramic Scaffolds for Regenerative Medicine. Bioceram Dev Appl 5: 082. doi: 10.4172/2090-5025.1000082

Copyright: (c) 2015 Hannickel A, et al. This is an open-access article distributed under the terms of the Creative Commons Attribution License, which permits unrestricted use, distribution, and reproduction in any medium, provided the original author and source are credited. 
Citation: Hannickel A, Prado da Silva MH (2015) Novel Bioceramic Scaffolds for Regenerative Medicine. Bioceram Dev Appl 5: 082. doi: 10.4172/2090-5025.1000082

Page 2 of 3

The scaffolds of bovine origin were produced by heat treating bovine trabecular bone blocks $\left(10 \times 10 \times 10 \mathrm{~mm}^{3}\right)$ at $900^{\circ} \mathrm{C}$ with a path at $550^{\circ} \mathrm{C}$ and heating rates of $0.5^{\circ} \mathrm{C} / \mathrm{min}$ and $5^{\circ} \mathrm{C} / \mathrm{min}$. The so obtained bone mineral were impregnated with a niobo-phosphate glass. The niobo-phosphate glass has the molar composition of $0.3 \mathrm{M} \mathrm{Nb}_{2} \mathrm{O}_{5}$, $0.3 \mathrm{M} \mathrm{P}_{2} \mathrm{O}_{5}, 0.2 \mathrm{M} \mathrm{CaO}$ and $0.2 \mathrm{M} \mathrm{CaF}_{2}$. Reagent grade $\mathrm{H}_{3} \mathrm{PO}_{4}$ and $\mathrm{Nb}_{2} \mathrm{O}_{5}$ were used as network former sources and $\mathrm{CaF}_{2}$ and $\mathrm{CaCO}_{3}$ were used as glass modifiers sources. The reagents were mixed, magnetically stirred overnight and molten in a platinum crucible at $1350^{\circ} \mathrm{C}$. The glasses were rapidly cooled in water, dried in an oven at $100^{\circ} \mathrm{C}$ and ground to a medium particle size $0.18 \mu \mathrm{m}$. The bone mineral blocks were immersed in glass suspensions in ethanol and sintered at $1350^{\circ} \mathrm{C}$. In previous studies, defined fractions of glass were incorporated to bone mineral powder and characterized by XRD [14]. XRD analyses of the impregnated porous blocks confirmed the glass fraction obtained by weighting the blocks before and after impregnation.

The structural analysis of the scaffolds were assessed by X-Ray Diffraction (XRD) using a Panalytical X"PERT PRO diffractometer with $\mathrm{CuKa}$ radiation, a scanning step of $0.05^{\circ}$ and a collecting time of 8 seconds per step. Rietveld analyses were performed using the academic version of TOPAS program. Scanning electron microscopy (SEM) analyses of the struts were performed in a Jeol JSM-5800 LV scanning electron microscope. Fourier transform-infrared spectroscopy (FTIR Prestige-21/ Shimadzu) analyses were used to assess the present functional groups on the specimens.

\section{Results and Discussion}

Scanning Electron Microscopy (SEM) analyses of the scaffolds showed an open porous structure with pore sizes larger than $100 \mu \mathrm{m}$. This requirement allows not only cell colonization but bone ingrowth and vascularisation of newly formed bone. Figures 1-3 show images

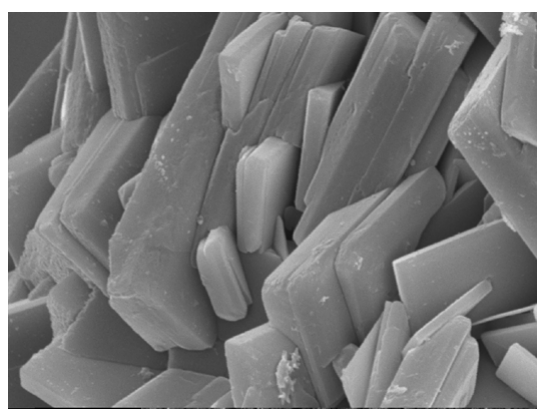

Figure 1: SEM micrograph of sponge coated with monetite at $4500 \mathrm{X}$

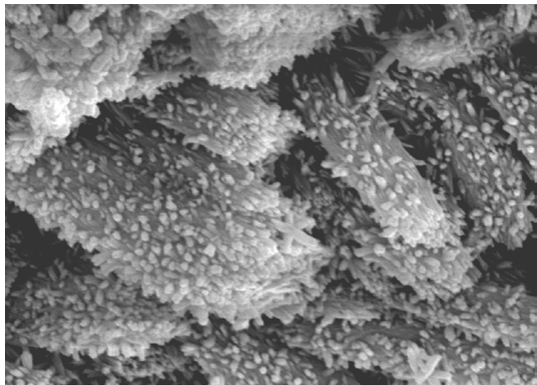

Figure 2: SEM micrograph of the above coating converted to hydroxyapatite at $10000 \mathrm{X}$

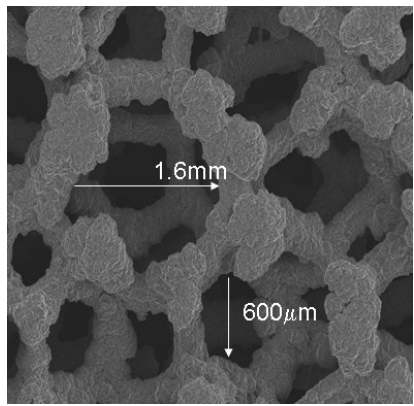

Figure 3: SEM micrograph of HA coated sponge after sintering at $1300^{\circ} \mathrm{C}$ at $33 \mathrm{X}$

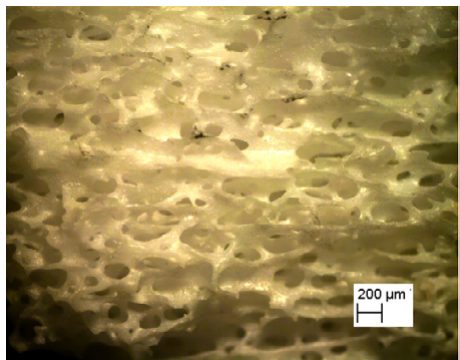

Figure 4: Light micrograph of bone mineral after sintering at $1350^{\circ} \mathrm{C}$.

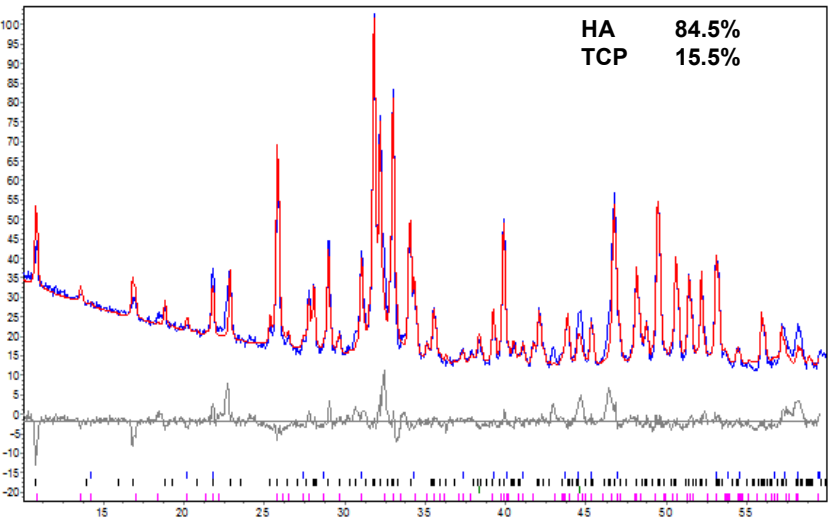

Figure 5: XRD analysis of bone mineral with $4 w t \%$ glass after sintering at $1350^{\circ} \mathrm{C}$

from scaffolds derived from polyurethane sponges. In Figure 1 a detail of the monetite coating can be observed by SEM. After conversion, the monetite crystals give rise to hydroxyapatite nanocrystals, as can be seen in Figure 2. However, the original shape of monetite is maintained. Figure 3 shows the scaffold morphology after sintering.

In a previous study, the authors show the XRD patterns of these scaffolds before and after conversion, as well as after sintering. Figure 4 shows the light micrograph of a glass reinforced hydroxyapatite scaffold derived from bovine, after sintering at $1350^{\circ} \mathrm{C}$. It is clear that the morphological requirements of open and interconnected pores were met. It is worth to mention that one advantage of this route of scaffold production is the maintenance of the natural bone structure.

Figure 5 shows the blue and red lines correspond to theoretic and 
Citation: Hannickel A, Prado da Silva MH (2015) Novel Bioceramic Scaffolds for Regenerative Medicine. Bioceram Dev Appl 5: 082. doi:

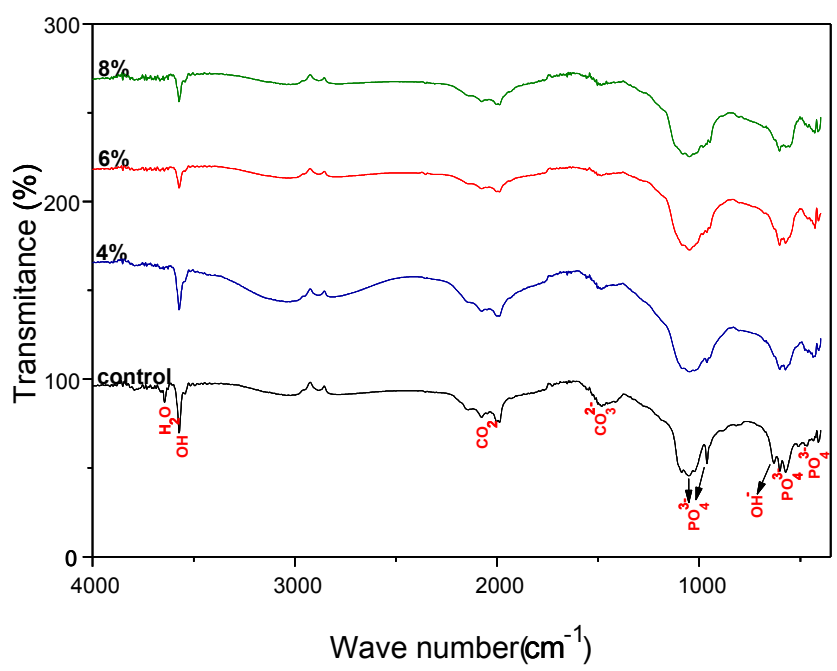

Figure 6: FTIR analyses of bone mineral (control) and glass reinforced bone mineral.

experimental patterns for the glass reinforced scaffolds can develop several different microstructures, depending on the glass fraction added and sintering temperature.

Figure 6 shows the XRD result for samples with $4 \mathrm{wt} \%$ glass and sintered at $1350^{\circ} \mathrm{C}$. The Rietveld analysis identified $84.5 \mathrm{wt} \% \mathrm{HA}$ and $15.5 \mathrm{wt} \%$ of $\beta$-TCP. The control of the fraction of TCP allows the development of scaffolds with resorption rates compatible with new bone formation rates. FTIR analyses of control samples (without glass) and GR-HA samples. It is clear that the more the fraction of TCP, the less intense is the $\mathrm{OH}^{-}$band at $3570 \mathrm{~cm}^{-1}$.

\section{Conclusions}

The present study points to the possibility of using highly crystalline ceramics, but still resorbable, as the crystalline phases are not only hydroxyapatite, but also the more resorbable tricalcium phosphates.

Another approach that this study aims to present concerns the use of bovine scaffolds impregnated with bioactive glass and sintered at high temperature, i.e. $1350^{\circ} \mathrm{C}$, which is unusual for hydroxyapatite scaffolds. High temperature sintering of glass-reinforced bovine blocks fostered HA decomposition into TCP.

\section{References}

1. Letra A, Menezes R, Granjeiro JM, Vieira AR (2009) AXIN2 and CDH1 polymorphisms, tooth agenesis, and oral clefts. Birth Defects Res A Clin Mol Teratol 85: 169-73.

2. Kohal RJ (1998)The effects of guided bone regeneration and grafting on implants placed into immediate extraction sockets. An experimental study in dogs. J Periodontol 69: 927-37.

3. Pradoda Silva MH, Lopes MA (2002) Production of porous biomaterials based on glass-reinforced hydroxyapatite composites, Advanced Materials Forum I 230: 483-486.

4. Pradoda Silva MH, Santosa JD (2002) Porous glass reinforced hydroxyapatite materials produced with different organic additives. Journal of Non-Crystalline Solids 304: 286-292.

5. Albuquerque JSV (2003) Porous bioceramics produced with calcium phosphate nanoparticles. Bioceramics 240: 23-26.

6. Albuquerque JSV (2004) Porous triphasic calcium phosphate bioceramics. Bioceramics 254: 1021-1024.

7. Queiroza AC, Santos JD, Monteiro FJ, Pradoda MH (2003) Dissolution studies of hydroxyapatite and glass reinforced hydroxyapatite ceramics. Materials Characterization 50: 197-202.

8. Hench LL, Polak JM (2002) Third-generation biomedical materials. Science 295: 1014-1017.

9. Sepulveda $\mathrm{P}(2000)$ Properties of highly porous hydroxyapatite obtained by the gelcasting of foams. Journal of the American Ceramic Society 83: 3021-3024.

10. Mishima FD (2011) Hydroxyapatite scaffolds produced by hydrothermal deposition of monetite on polyurethane sponges substrates. Bioceramics 493: 820-825.

11. LeGeros RZ (1991) Calcium phosphates in oral biology and medicine. Monogr Oral Sci 15: 1-201

12. Mavropoulos E, daRocha NCC, Kede MLFM, Prado da Silva MH, Moreira JC, et al. (2008) Process for porous interconnected substrate coating, synthesis intermediate and obtained porous product 396: 561-564.

13. Prado da Silva MHS, ROSSI AM (2009) Biovidros e Compósitos Altamente Biocompatíveis.

14. Silva CLAD (2009) Efeito da adição de biovidro na hidroxiapatita de origem bovina, in Mechanics and Materials Engineering. Military Institute of Engineering: Rio de Janeiro. 